\title{
A BRAIN TUMOR MIMICKING BRAIN ABSCESS
}

\author{
Achmad Harun Muchsin*, Rachmat Faisal Syamsu**, Armanto Makmun** \\ *Lecturer at Department of Anatomy, Medical Faculty of Indonesia Muslim University, Makassar \\ **Lecturer at Department of Public Health, Medical Faculty of Indonesia Muslim University, \\ Makassar
}

\begin{abstract}
A brain tumor could be mimicking brain abscess in some cases. Not just in imaging but also both of has a similar symptoms, physician must anamnesis properly and run several tests. A brain abscess is an intraparenchymal collection of pus. The incidence of brain abscesses is approximately $8 \%$ of intra-cranial masses in developing countries and $12 \%$ in the western countries.

In this case, we reports a male patient with gradually left hemiplegia, left deviation of tongue, left hemifacial paresis, and visual hallucination and psychological disturbance. Initial imaging showed the possibilities of space occupying lessions (SOL) with suspect to Astrocytoma. But, based from the history taking, there is bad habit of oral hygiene, that the patient usually sticks his gum with tooth stick and after confirmation from second head CT scan with contrast enhancement, confirmed right cerebral abscess with perifocal oedem. $\quad$ After 2 weeks empirical antibiotic therapy, there is significant clinically improvement. But, after we confirm with second Head CT scan with contrast enhancement, there is a very minimum decreased size of the abscess lesion, so surgical drainage is indicated. We collect Xanthochromic liquid from surgical drainage (not purulent), and from microscopic evaluation inflammation lesion confirmed. But by microbiological culture, there is no growth of aerobic bacteria from drainage liquid culture, we assume because of empirical antibiotic therapy was started before the microbiological culture test. After surgical drainage, there is no complication, and clinical become more improve.
\end{abstract}

Keywords : Brain Abscess, Tumor-like, Astrocytoma, Xanthocromic, Surgical Drainage, Antibiotic Empiric Therapy. 


\section{BACKGROUND}

Differentiation between tumors and tumor-like lesions of the central nervous system is essential for planning adequate treatment and for estimating outcome and future prognosis. Neuroimaging fulfills an essential role in the correct differentiation between both entities. Intracranial abscesses may present with imaging features that are identical to high-grade neoplasms such as a glioblastoma multiforme. Differentiation has been difficult for many years. On conventional imaging abscesses are round, mass lesions with various degrees of adjacent vasogenic white matter edema and a strong peripheral contrast enhancement. ${ }^{1}$

A brain abscess is an intraparenchymal collection of pus. The incidence of brain abscesses is approximately $8 \%$ of intracranialmasses in developing countries and $12 \%$ in the western countries.Brain abscess is a focal, intracerebral infection that begins as a localized area of cerebritis and develops into a collection of pus surrounded by a wellvascularized capsule ${ }^{2}$.

\section{DISCUSSION}

The most frequent clinical manifestation of brain abscess is headache. Fever and altered level of consciousness are frequently absent. Neurologic signs depend on the site of the abscess and can be subtle for days to weeks. Behavioral changes may occur in patients with abscesses in the frontal or right temporal lobes. Patients with abscesses in the brain stem or cerebellum may present with cranial-nerve palsy, gait disorder, or either headache or altered mental status owing to hydrocephalus. Up to $25 \%$ of patient present with seizures ${ }^{2,3}$. In this patient as the brain abscess located at the right temporoparietal, he experience visual hallucination and psychological disturbance, but there is no seizure occur.

\begin{tabular}{lc}
\hline Sign/symptom & Frequency $(\%)$ \\
\hline Fever & $54.5-60$ \\
Headache & $72-92.8$ \\
Hemiparesis/cranial nerve & 14.5 \\
Hemiparesis & 20.2 \\
No neurological deficit & 39.8 \\
Meningism & 52.2 \\
Altered level of consciousness & $10-100$ \\
Seizure & $21-25.3$ \\
Nausea/vomiting & $31-40$ \\
Papilledema & $4.1-50$ \\
GCS, at admission & \\
3-8 & 10.3 \\
9-12 & 28.0 \\
$13-15$ & 61.7 \\
\hline
\end{tabular}

Table 1. Common signs and symptoms in Brain Abscess

Once the bacteria enter, there will be an evolutionary process abscess formation through four stages, namely ${ }^{2,3,4}$ :

1. Early cerebritis (days 1 to 3 ): This stage is typified by neutrophyl accumulation, tissue necrosis, and edema. This is the moment for microglial and astrocyte activation that longs through abscess development.

2. Advanced cerebritis (day 4 to 9): This phase is associated with a predominant macrophage and lymphocyte infiltrate.

3. Formation of the capsule early (day 10 to 13): Resolution cerebritis area, associated with the formation of a well-vascularized abscess wall.

4. The formation of the final capsule ( $\geq$ day 14): mature capsule surrounding area containing debris and inflammatory PMN cells, cerebral edema more widespread.

Localized inflammatory exudate, septic thrombosis of vessels, and aggregates of degenerating leukocytes represent the early reaction to bacterial invasion of the brain. Surrounding the necrotic tissue are macrophages, astroglia, microglia, and many small veins, some of which show endothelial hyperplasia, contain fibrin, and are cuffed with polymorphonuclear leukocytes. The term 
cerebritis is loosely applied to this local suppurative encephalitis or immature abscess. Within several days, the intensity of the reaction begins to subside and the infection tends to become delimited. The center of the abscess takes on the character of pus; at the periphery, fibroblasts proliferate from the adventitia of newly formed blood vessels and form granulation tissue, which is readily identified pathologically within 2 weeks of the onset of the infection but it is evident earlier as restriction of diffusion on MRI. As the abscess becomes more chronic, the granulation tissue is replaced by collagenous connective tissue. It has also been noted, both in experimental animals and in humans; that the capsule of the abscess is not of uniform thickness ${ }^{2}$.

CT and MRI are the most important diagnostic tools. In the CT scan, the capsule of the abscess enhances and the center of the abscess and surrounding edematous white matter are hypodense. With MRI, in Tlweighted images, the capsule enhances and the interior of the abscess is hypointense and shows restricted diffusion; in T2-weighted images, the surrounding edema is apparent and the capsule is hypointense and there is variable diffusion restriction within the lesion. Practically all abscesses larger than $1 \mathrm{~cm}$ produce positive scans ${ }^{1}$.

Brain abscess is the only CNS infection in which a lumbar puncture (LP) is never recommended and may even be contraindicated. In the Nathoo et al. series, pretransfer LP had been performed in 193 patients $(19.8 \%)$ before consultation, which was followed by neurological deterioration in 26 patients $(13.5 \%)$, with 7 deaths. CSF analysis revealed nonspecific pleocytosis with increased protein and no organism cultured in 80 patients $(41.5 \%)$, bacterial meningitis in 71 patients (36.8\%), and was normal in 31 patients. No data were available in 11 patients. This advice is not only because an LP does not help in the diagnosis but also because increased ICP is often present as a result of the mass effect, which increases the likelihood of herniation. ${ }^{4}$

We confirm the brain abscess diagnosis based from cytological of drainage fluid, that smear preparation consists of cells lymphocyte and macrophage cyst, and malignant epithelial cells not appear on this preparation. Although, microbiological culture result found there is no growth of aerobic bacteria.

In general, the selection of empirical antibiotic regimen as first-line treatment of cerebral abscess is based on the source of infection $^{5,6,7}$ :

1. Expansion directly from the sinuses, teeth, middle ear : penicillin $\mathrm{G}+$ Metronidazole + cephalosphorin generation III

2. The spread via hematogenous know Trauma penetration head: nafcillin + Metronidazole + III generation cephalosporins

3. Post Operation: vancomisisn (for MRSA) + ceftazidime or cefepime (pseudomonas)

4. There were no predisposing factors: Metronidazole + Vancomycin + third generation cephalosporins.

Because the source of infection in this case is from teeth, so we give triple antibiotics Ampicillin, Metronidazole, and Ceftriaxone. After 2 weeks antibiotics was given, there is significant clinically improvement such as strength from score 0 become 4 , and there is also improvement of mental status. But, after we confirm with another Head CT scan with contrast enhancement there is a very minimum decreased size of the abscess lesion (from 4.69 $\mathrm{x} 3.7 \mathrm{~cm}$ to $4.9 \times 3.8 \mathrm{~cm}$ ), so surgical drainage is indicated. After surgical, no more mental problem occur, and motoric function was improve.

Medical treatment without operative measures considered on the condition such as single abscess, which size were less than $2 \mathrm{~cm}$. 
Multiple abscesses or which location were difficult to reach. And if patient in critical conditions, in the end stage of the disease..$^{4,7}$

Surgical drainage or excision of cerebral abscess is indicated for lesions with diameter> $2.5 \mathrm{~cm}$,there is a significant mass effect, lesions close to the ventricles, neurological condition worsens, after giving therapy within 2 weeks there is enlargement of the abscesses, or after 4 weeks therapy the abscess size is not decrease. $^{4,7}$

\section{TESTS AND IMAGING}

\section{Head CT Scan (without contrast \\ enhancement) on 5-12-2016:}
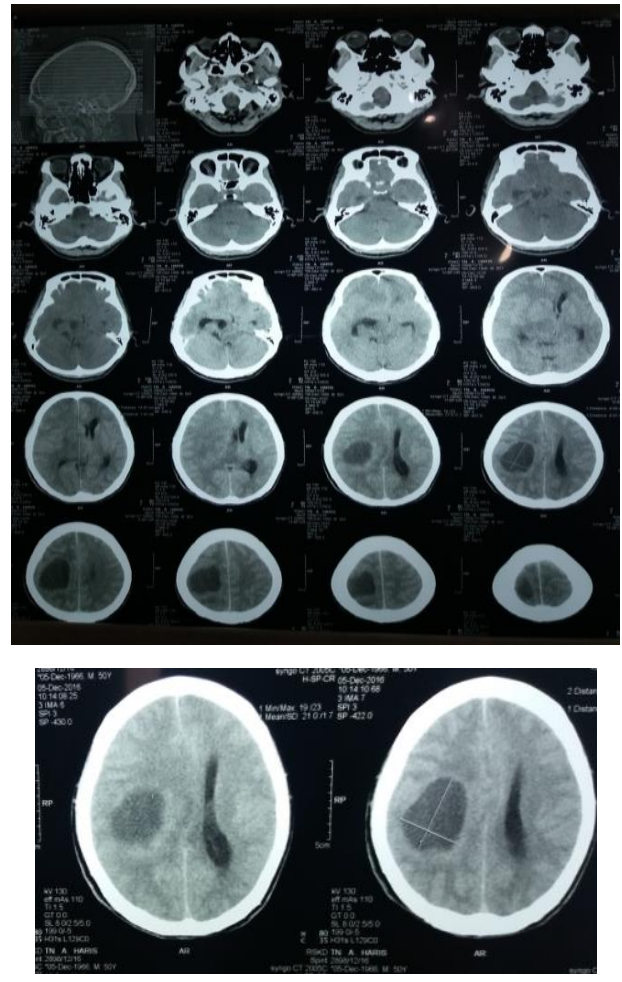

\section{Head CT Scan non contrast axial:}

- Clear define border mass at right temporoparietal region with density 21 $\mathrm{HU}$ which pressing ventricle system to the right and causing midline shift to the left $\pm 1,52 \mathrm{~cm}$, size $4 \times 4,91 \mathrm{~cm}$.
According to the "Infection in Neurosurgery' Working Party Of The British Society For Antimicrobial Chemotherapy," the guiding principles for surgical management are: to urgently reduce raised intracranial pressure by aspiration of the cavity using image guidance; To confirm the diagnosis; To obtain pus for microbiological diagnosis; To enhance the efficacy of antibiotic therapy; and to avoid iatrogenic spread of infection into the ventricles. ${ }^{4}$

- Ventricle system seems narrow

- Sulci and gyri in normal limit

- CPA,Pons, and Cerebellum in normal limit.

- Paranasalsinuses and aircell mastoid in normal limit.

- Both of bulbusocculi and retrobulbar structure in normal limit.

- Bones intact

Interpretation: Cerebral Abscess DD/ Suggestive Low Grade Astrocytoma Advice: Head CT Scan with contrast enhancement

\section{$\underline{\text { Head CT Scan with contrast }}$}

enhancement 14-12-2016:

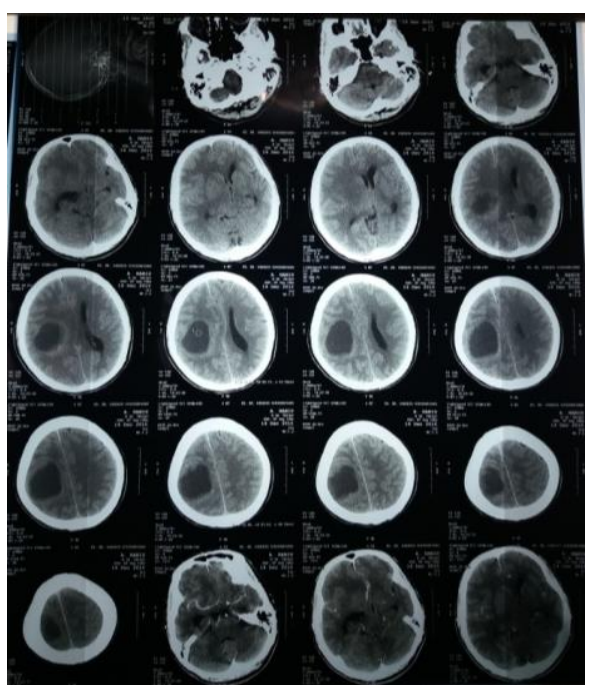


Head CT Scan with contrast enhancement on axial reformat, coronal and sagital view:

- Appear hypodense lesion with rim enhancement on post contrast, clear defined border, ireguler, non calsification, size $4.9 \times 3.8 \mathrm{~cm}$ at right lobus temporoparietal with perifocal oedema which pressing and narrowing right ventricle system and causing midline shit to the left $1.4 \mathrm{~cm}$.

- CPA, Pons, and Cerebellum WNL

- Physiological calcification on pineal body

- Paranasal sinuses and aircell mastoid WNL

- Both of bulbusocculi and retrobulbar structure WNL

- Bones intact

Interpretation: Sugestive Right

Cerebral Abscess DD/ Cyst Astrocytoma

\section{$\underline{\text { Head CT Scan with contrast enhancement }}$}

\section{4-01-2017:}

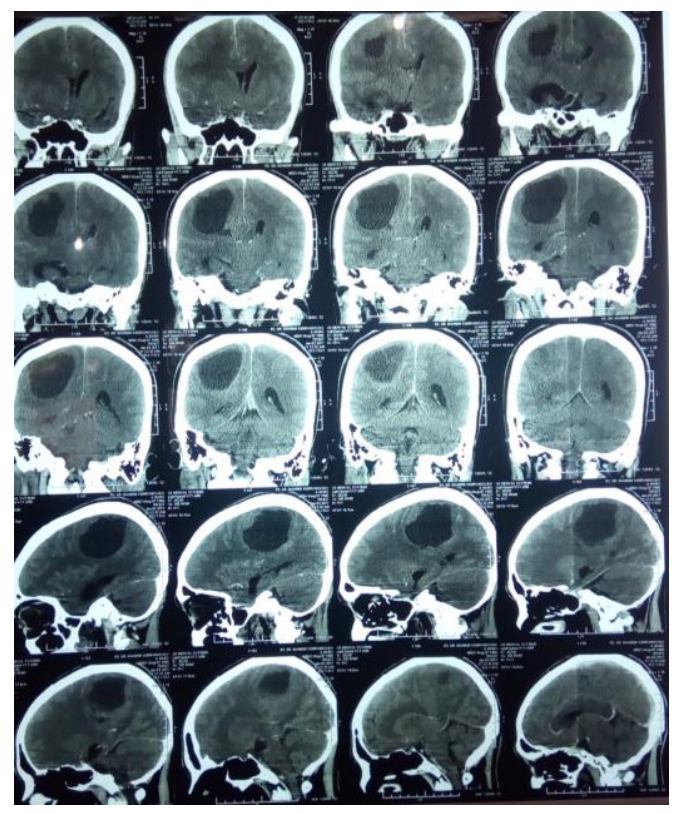

- Appear hypodense lesion (12 HU) with rim enhancement on post contrast, clear defined border, ireguler, non calsification, size $4.69 \times 3.7 \mathrm{~cm}$ at right lobus temporoparietal with perifocal oedema which pressing and narrowing right ventricle system and causing midline shit to the left $\pm 1 \mathrm{~cm}$.

- CPA, Pons, and Cerebellum WNL

- Physiological calcification on pineal body

- Paranasal sinuses and aircell mastoid WNL

- Both of bulbusocculi and retrobulbar structure WNL

- Bones intact

Interpretation: Sugestive Right Cerebral Abscess with improvement compared with recent CT Scan on 14/12/2016

\section{Surgery report (12/01/2017):}

- Patient in supine position under effect of general anesthesia

- Start disinfection and drapping procedure

- Horse shoe incision on right parietal, sharply deep until reach pericranium

- Start craniotomy until reach duramater, and hanging the duramater

- Open duramater, brain seems bulging, start puncture, collected fluid transparent-yellowish (Xanthochrome), and make PA Cytology.

- Start drainage with cytsosubaleal tube (omaya procedure) low pressure, patency test $(+)$

- Close duramater, fixates drainage tube on duramater, give fibrin glue.

- Start cranioplasty procedure and fixates with 3 miniplates med 2HSTRPLT and 
6 screw $1.6 x 5 \mathrm{~mm}$ autodrive 211 $16505 \mathrm{~A} 300$

- Bleeding control, close surgery wound layer per layer

- Operation finished.

Evaluation Result Cytology of Drainage Fluid (12/01/2017):

Microscopic: Smear preparation consists of cells lymphocyte and macrophage cyst.

Not appear malignant epithelial cells on this preparation.

Interpretation: Inflammation lesion

Microbiological Culture of Drainage Fluid Sample (18/01/2017):

There is no growth of Aerobic Bacteria

\section{CONCLUSSION}

Differentiation between tumors and brain abscess lesions of the central nervous system is essential for planning adequate treatment and for estimating outcome and future prognosis. Several tests including microbiological culture of abscess drainage liquid must be made to maintain diagnosis. After 2 weeks empirical antibiotic therapy and surgical drainage, there is no complication, and clinical become more improve.

\section{REFERENCES}

1. Huisman TAGM. Tumor-like lesions of the brain. Cancer Imaging. 2009 Oct 2;9 (Special issue A):S10-3.

2. Ropper H Allan, Samuels A Martin, Klein P Joshua. Principles of Neurology. Adams and Victor's. Tenth edition. McGraw- Hill education. United States. 2014. Pg 714-717.

3. Scheld M.W, Morra C.M, Whitley R.J. Brain Abscess in Bacterial and Mycoplasmal Infections. Infections of The Central Nervous System Fourth Edition.
Lippincott Williams \& Wilkins. Philadelpia. 2004

4. Brower M.C, Tunkel A.R, McKhann G.M, van de Beek D. Brain Abscess. The New England Journal of Medicine. N Engl J Med 2014;371:447-56. DOI 10.1056/NEJMra1301635. Accesed on 22nd August 2017.

5. Miranda et al. Brain Abscess: Current Management. Journal of Neuroscience in Rural Practice. 2013. Vol 4. Supplement 1. Wolter Kluwer. S67-SS76.

6. SMF Ilmu Penyakit Saraf. Abses Otak. Standar Pelayanan Medik (SPM) Bagian Ilmu Penyakit Saraf Fakultas Kedokteran Unhas. Pg 22-23

7. Misbach J, Hamid AB, Mayza, dkk. Abses Cerebri dalam Infeksi. Buku Pedoman Standar Pelyanan Medis (SPM) \& Standar Prosedur Operasioal (SPO). PERDOSSI. Jakarta.2006.

8. Bintoro A.C. Abses Serebri dalam Infeksi pada Sistem Saraf. Kelompok Studi Neuro Infeksi. Airlangga University Press. Surabaya.2011. Pg 21-9. 
